\title{
Improvement of Back and Leg Pain after Lumbar Spinal Decompression without Fusion
}

\author{
Matthias Florian Geiger ${ }^{1}$ Nicola Bongartz ${ }^{1}$ Christian Blume ${ }^{1}$ Hans Clusmann ${ }^{1}$ \\ Christian Andreas Müller ${ }^{1}$ \\ ${ }^{1}$ Department of Neurosurgery, Medical Center University of Aachen, \\ RWTH University, Aachen, NRW, Germany \\ Address for correspondence Dr. Matthias Florian Geiger, Department \\ of Neurosurgery, Medical Center University of Aachen, RWTH \\ University, Aachen, NRW 52074, Germany \\ J Neurol Surg A 2019;80:81-87. \\ (e-mail: mgeiger@ukaachen.de).
}

\begin{abstract}
Keywords

- lumbar spinal stenosis

- decompression

- re-decompression

- outcome

- leg and back pain

Background To evaluate whether decompression in lumbar spinal stenosis without fusion leads to sufficient improvement of back pain and leg pain and whether redecompression alone is sufficient for recurrent lumbar spinal stenosis for patients without signs of instability.

Material and Methods A successive series of 102 patients with lumbar spinal stenosis (with and without previous lumbar surgery) were treated with decompression alone during a 3-year period. Data on pre- and postoperative back pain and leg pain (numerical rating scale [NRS] scale) were retrospectively collected from questionnaires with a return rate of $65 \%(n=66)$. The complete cohort as well as patients with first-time surgery and redecompression were analyzed separately. Patients were dichotomized to short-term followup ( $<100$ weeks) and long-term follow-up ( $>100$ weeks) postsurgery.

Results Overall, both back pain (NRS 4.59 postoperative versus 7.89 preoperative; $p<0.0001$ ) and leg pain (NRS 4.09 versus $6.75 ; p<0.0001$ ) improved postoperatively. The short-term follow-up subgroup $(50 \%, n=33)$ showed a significant reduction in back pain (NRS 4.0 versus $6.88 ; p<0.0001$ ) and leg pain (NRS 2.49 versus 6.91: $p<0.0001$ ). Similar results could be observed for the long-term follow-up subgroup $(50 \%, n=33)$ with significantly less back pain (NRS 3.94 versus $7.0 ; p<0.0001)$ and leg pain (visual analog scale 3.14 versus 5.39; $p<0.002$ ) postoperatively. Patients with previous decompression surgery benefit significantly regarding back pain (NRS 4.82 versus 7.65; $p<0.0024$ ), especially in the long-term follow-up subgroup (NRS 4.75 versus 7.67; $p<0.0148$ ). There was also a clear trend in favor of leg pain in patients with previous surgery; however, it was not significant.

Conclusions Decompression of lumbar spinal stenosis without fusion led to a significant and similar reduction of back pain and leg pain in a short-term and a long-term follow-up group. Patients without previous surgery benefited significantly better, whereas patients with previous decompression benefited regarding back pain, especially for long-term follow-up with a clear trend in favor of leg pain.
\end{abstract}

\section{Introduction}

Lumbar spinal stenosis is the most common reason for lumbar decompressive surgery, especially in elderly patients whose surgery rates have increased over the last decades. ${ }^{1,2}$

received

February 28, 2018

accepted after revision

May 25, 2018

published online

December 5, 2018

The aim of surgical intervention is to improve leg pain, walking distance, and further symptoms of spinal claudication. The benefit regarding low back pain is still a matter of debate. ${ }^{3-5}$ Also the treatment strategy for recurrent stenosis at the same level is unclear.

(C) 2019 Georg Thieme Verlag KG Stuttgart · New York
DOI https://doi.org/ 10.1055/s-0038-1669473. ISSN 2193-6315. 
For first surgery of spinal stenosis with low back pain, some authors prefer a decompression without fusion with a good clinical outcome even for back pain. ${ }^{6-8}$ Other groups report that patients with dominant back pain do not improve adequately from decompression surgery alone. ${ }^{4,5}$ Therefore, additional fusion or dynamic stabilization procedures are often applied. It is also known that the rate of fusion procedures in lumbar spinal stenosis steadily increases; ${ }^{1}$ however, the indication often remains unclear. ${ }^{9-11}$ Some evidence indicates that additional fusion does not lead to a better clinical and functional outcome than decompression alone. ${ }^{12}$ The rate for revision surgeries seems to be comparable in both groups. ${ }^{12}$ However, the hospital stay, surgical time, amount of blood loss, complication rates, and overall surgical costs were higher in patients with an additional fusion. ${ }^{12,13}$

Even more difficult is decision making in patients with recurrent lumbar spinal stenosis. A subanalysis of the SPORT trial in an 8-year follow-up showed a reoperation rate of $18 \%$ in patients initially treated for lumbar spinal stenosis independent of the initial surgical procedure with decompression alone versus decompression with fusion. Patients who did not require reoperation had better patient-reported outcomes at 8-year follow-up compared with those who had a new decompressive surgery. ${ }^{14}$

However, little is still known about pain reduction in patients with recurrent lumbar spine stenosis treated with re-decompression surgery alone.

Knowing the increasing number and older age of patients with degenerative spinal disease and taking into account the possible complications and costs for spinal instrumentation and fusion, we analyzed the improvement of back and leg pain after lumbar spinal decompression without fusion in a short-term and long-term follow-up for first-time surgery and in patients with previous decompression.

\section{Methods}

All patients with lumbar spinal stenosis, treated only with decompression during a 3-year period (2011-13), were collected retrospectively. Both patients with previous lumbar decompression and patients without previous surgery were included if there was no need for stabilization due to macroinstability as proven by dynamic X-ray and mobile slippage of at least $5 \mathrm{~mm}$. Patients' demographics, surgical parameters, and complications (surgical complications such as dural leak, rebleeding, and infection; medical complications such as thrombosis, pneumonia, urinary infection, and angina pectoris) were collected from the charts. Data on pre- and postoperative back pain and leg pain on a numeric rating scale (NRS) were collected retrospectively from questionnaires sent to patients. The NRS is a pain rating questionnaire. Patients are asked to indicate the intensity of their current pain. This selfreport measure uses an 11-point numeric scale, ranging from 0 ("no pain") to 10 ("worst pain imaginable"). ${ }^{15}$

The postoperative outcome regarding back pain and leg pain was then analyzed within the retrieved questionnaires. Afterward, the whole cohort was divided into two groups: first-time surgery (native) and recurrent surgery (recurrent).
Subgroup analysis was performed according to the period of postoperative follow-up: short-term follow-up subgroup ( $<100$ weeks between surgery and questionnaire) and longterm follow-up subgroup ( $>100$ weeks between surgery and questionnaire). The dichotomization at 100 weeks postsurgery was set at the medium time between surgery and data collection with the questionnaire in the whole cohort.

Surgical decompression was done unilaterally, unilaterally with contralateral undercutting, or bilaterally, depending on the individual preference of the surgeon. All surgical procedures were done microsurgically according to previously described techniques from Thomé et al. ${ }^{8}$ To exclude the influence of the surgical procedure, we separately analyzed the patient-reported outcome on the NRS for each technique within the complete cohort with respect to the sample size.

Statistical analysis was performed with GraphPad Prism 5 (San Diego, California, United States) using an unpaired $t$ test, chi-square test, and Fisher exact test. Significance level was set at $p<0.05$.

\section{Results}

\section{Patient Distribution}

Within a 3-year period, 102 patients with lumbar spinal stenosis treated with decompression alone could be identified from the patient database. From these patients, 76 had not had lumbar spine surgery before, and 26 were diagnosed with recurrent lumbar spine stenosis. We received 65 answers from the previously sent questionnaires (48 from native patients and 17 from recurrent patients) (-Fig. 1).

\section{Demographic and Baseline Characteristics}

The mean age of the cohort was 68 years. For patients with previous decompression, the mean age was 71 ; for patients without previous lumbar surgery, mean age was 67 years $(p=0.22)$. The duration of symptoms was 69 weeks ( \pm 110.3 weeks) for the complete group, 60.91 weeks ( \pm 69.85 weeks) for patients without previous decompression, and 52.7 weeks ( \pm 76.71 weeks) with previous decompression $(p=0.7067)$. The mean body mass index in the complete

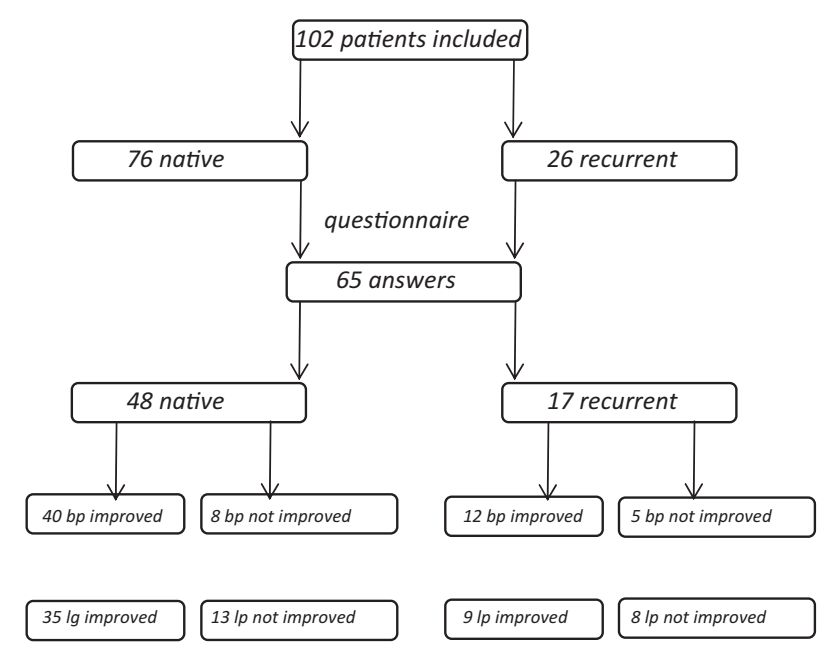

Fig. 1 Patient distribution. bp, back pain; Ip, leg pain. 
Table 1 Demographic and baseline characteristics

\begin{tabular}{|l|l|l|l|l|}
\hline & Complete cohort & $\begin{array}{l}\text { Without previous } \\
\text { decompression }\end{array}$ & $\begin{array}{l}\text { With previous } \\
\text { decompression }\end{array}$ & $p^{\text {a }}$ \\
\hline Cases, $n(\%)$ & 102 & $76(74.5)$ & $26(25.5)$ & \\
\hline Women, $n(\%)$ & $45(46)$ & $34(44.7)$ & $11(42.3)$ & 0.652 \\
\hline Mean age, $y( \pm$ SD) & $68( \pm 11.2)$ & $67( \pm 10.6)$ & $71( \pm 12.6)$ & 0.22 \\
\hline Duration of symptoms, wk (mean \pm wk) & $69( \pm 110.3)$ & $60.91( \pm 69.85)$ & $52.7( \pm 76.71)$ & 0.7067 \\
\hline BMI, mean $( \pm$ SD) & $29.56( \pm 5.93)$ & $29.5( \pm 5.704)$ & $29.97( \pm 6.733)$ & 0.7389 \\
\hline ASA, mean $( \pm$ SD) & $2.474( \pm 0.5806)$ & $2.472( \pm 0.5559)$ & $2.5( \pm 0.6726)$ & 0.8458 \\
\hline Patients with diabetes mellitus, $n(\%)$ & 17 & $13(17.1)$ & $4(15.4)$ & 0.8574 \\
\hline Hypertension, $n(\%)$ & 59 & $42(55.3)$ & $17(65.4)$ & 0.1593 \\
\hline Kidney disease, $n(\%)$ & 7 & $4(5.3)$ & $3(11.5)$ & 0.2661 \\
\hline Smoking, $n(\%)$ & 13 & $9(11.8)$ & $4(15.4)$ & 0.6405 \\
\hline Tumor history, $n(\%)$ & 2 & $2(2.6)$ & 0 & 0.4635 \\
\hline Length of hospital stay, d ( \pm SD) & $7.1( \pm 4.7)$ & $6.5( \pm 3.9)$ & $8.8( \pm 6.3)$ & $<0.03$ \\
\hline
\end{tabular}

Abbreviations: ASA, American Society of Anesthesiologists; BMI, body mass index; SD, standard deviation.

${ }^{a}$ The $p$ value is measured for patients with and without previous surgery.

cohort was $29.56( \pm 5.93)$ and $29.5( \pm 5.704)$ versus 29.97 ( \pm 6.733 ), that is, pre-adiposity, for patients without or with previous decompression $(p=0.7389)$. The mean American Society of Anesthesiologist score showed a moderate but definite systemic disturbance, $2.472( \pm 0.5559)$ for patients without previous surgery and $2.5( \pm 0.6726)$ for the group with previous decompression (0.8458). The hospital stay for patients with previous lumbar decompression was significantly longer (8.8 days \pm 6.3 versus 6.5 days \pm 3.9 ; $p=0.031$ ). - Table 1 lists the other nonsignificant incidences of medical disease, smoking, alcohol, or tumor history within our cohort.

\section{Surgical Characteristics}

The mean operating time per operated level for all patients was 124.7 minutes ( \pm 88.97 minutes). For patients with previous lumbar decompression, the surgical time per level was significantly longer (189.1 \pm 126.8 minutes), compared with the group without previous surgery $(102.1 \pm 56.8$ minutes; $p<0.0001)$. The mean number of levels of decompression were $1.8 \pm 0.8645$, ranging from 1 to 5 . For the group with previous surgery, the number of levels approached was $1.9 \pm 1.038$ standard deviation(SD) ranging from 1 to 5 versus $1.8 \pm 0.8003$ SD ranging from 1 to 4 for the group without previous surgery ( $p=0.421$; - Table 2).

Table 2 Intraoperative data

\begin{tabular}{|c|c|c|c|c|}
\hline & Complete cohort & $\begin{array}{l}\text { Without previous } \\
\text { decompression }\end{array}$ & $\begin{array}{l}\text { With previous } \\
\text { decompression }\end{array}$ & $p^{\mathrm{a}}$ \\
\hline Operative time per level, mean \pm (min)] & $124.7( \pm 88.97)$ & $102.1( \pm 56.8)$ & $189.1( \pm 126.8)$ & 0.0001 \\
\hline $\begin{array}{l}\text { Mean levels of decompression }( \pm S D) \text {, } \\
\text { range }\end{array}$ & $1.8( \pm 0.8645), 1-5$ & $1.8( \pm 0.8003), 1-4$ & $1.9( \pm 1.038), 1-5$ & 0.421 \\
\hline \multicolumn{5}{|l|}{ Major complications, $n$} \\
\hline Postoperative paresis of the foot & 1 & 1 & 0 & \\
\hline \multicolumn{5}{|l|}{ Minor complications, $n$} \\
\hline Pneumonia & 1 & 1 & 0 & \\
\hline Sepsis & 1 & 1 & 0 & \\
\hline Angina pectoris & 1 & 1 & 0 & \\
\hline $\begin{array}{l}\text { Epidural hematoma needing revision } \\
\text { surgery }\end{array}$ & 1 & 1 & 0 & \\
\hline Wound infections, $n$ (\%) & $3(2.9)$ & $\begin{array}{l}2(2.6) \\
\text { one with need of } \\
\text { revision surgery }\end{array}$ & $1(3.8)$ & 0.99 \\
\hline
\end{tabular}

${ }^{\text {a }}$ The $p$ value is measured for patients with and without previous surgery. 
Table 3 Affected levels

\begin{tabular}{|l|l|l|l|}
\hline & $\begin{array}{l}\text { Complete } \\
\text { cohort, } \\
n\end{array}$ & $\begin{array}{l}\text { Without } \\
\text { previous } \\
\text { decompression, } \\
n\end{array}$ & $\begin{array}{l}\text { With } \\
\text { previous } \\
\text { decompression, } \\
n\end{array}$ \\
\hline T12-L1 & 1 & 1 & 0 \\
\hline L1-L2 & 3 & 1 & 2 \\
\hline L2-L3 & 28 & 18 & 10 \\
\hline L3-L4 & 54 & 37 & 17 \\
\hline L4-L5 & 80 & 62 & 18 \\
\hline L5-S1 & 22 & 18 & 4 \\
\hline
\end{tabular}

Table 4 Procedure of decompression

\begin{tabular}{|l|l|l|l|}
\hline & $\begin{array}{l}\text { Unilateral, } \\
\boldsymbol{n}(\%)\end{array}$ & $\begin{array}{l}\text { Unilateral with } \\
\text { undercutting, } \\
\boldsymbol{n}(\%)\end{array}$ & $\begin{array}{l}\text { Bilateral, } \\
\boldsymbol{n}(\%)\end{array}$ \\
\hline $\begin{array}{l}\text { Complete } \\
\text { cohort }\end{array}$ & $30(29)$ & $53(52)$ & $19(19)$ \\
\hline $\begin{array}{l}\text { Without } \\
\text { previous } \\
\text { decompression }\end{array}$ & $19(25)$ & $43(57)$ & $14(18)$ \\
\hline $\begin{array}{l}\text { With previous } \\
\text { decompression }\end{array}$ & $11(42)$ & $10(38)$ & $5(19)$ \\
\hline
\end{tabular}

We detected one major complication in the group without previous surgery with a new and persisting postoperative paresis of foot elevation. Also some single minor complications were seen in the group without previous surgery (-Table 2). The rate of wound infection was $2.9 \%$ for the complete cohort and 2.6 versus $3.8 \%$ for patients without or with previous decompression $(p=0.99)$. - Table 3 describes the distribution of the treated levels.

The surgical procedures were unilateral decompression, unilateral decompression with contralateral undercutting, or bilateral decompression ( - Table 4 ). All patients with recurrent stenosis $(n=26)$ were re-decompressed at the index level; $57 \%(n=12)$ were additionally decompressed on an adjacent level.

\section{Outcome According to Questionnaires}

The return rate from the questionnaires was $66 \%(n=65)$. These 65 patients were used for further analyses for the preand postoperative NRS value for back pain and leg pain. The mean time between surgery and questionnaire was 100 weeks, ranging from 35 to 146 weeks. Thus to differentiate outcome, the cohort was dichotomized to a shortterm follow-up ( $<100$ weeks; $n=33$ ) and a long-term follow-up ( $>100$ weeks; $n=32$ ).

Preoperative back pain was described retrospectively as more severe than leg pain in the whole patient group $(p=0.0098)$. Regarding subgroups, this finding was present in the subgroup of patients without previous decompression $(p=0.0118)$ but not in the subgroup with previous lumbar surgery $(p=0.4286)$.

Independent from the time between surgery and questionnaire, the whole cohort improved significantly from 7.89 preoperatively to 4.53 postoperatively $(p<0.0001$ ) regarding NRS back pain, and leg pain with 6.75 versus 4.09 $(p<0.0001)$. Patients in the group without previous lumbar decompression $(n=48)$ profited significantly regarding back pain (7.98 versus $4.5 ; p<0.0001)$ and leg pain (6.69 versus 3.67; $p<0.0001$; - Table 5). Patients with previous lumbar decompression ( $n=17$ ) showed a significant reduction in back pain (7.65 versus $4.82 ; p<0.0024$ ), but no

Table 5 Outcome for back pain and leg pain

\begin{tabular}{|c|c|c|c|c|c|c|c|}
\hline & $\begin{array}{l}\text { Patients, } \\
n(\%)\end{array}$ & $\begin{array}{l}\text { NRS preoperative } \\
\text { back pain }( \pm S D)\end{array}$ & $\begin{array}{l}\text { NRS postoperative } \\
\text { back pain }( \pm S D)\end{array}$ & $p$ value & $\begin{array}{l}\text { NRS preoperative } \\
\text { leg pain }( \pm S D)\end{array}$ & $\begin{array}{l}\text { NRS postoperative } \\
\text { leg pain }( \pm S D)\end{array}$ & $p$ value \\
\hline \multicolumn{8}{|l|}{ General outcome } \\
\hline Complete cohort & $65(100)$ & $7.89( \pm 2.19)$ & $4.59( \pm 2.37)$ & $<0.0001$ & $6.75( \pm 2.73)$ & $4.09( \pm 2.54)$ & $<0.0001$ \\
\hline $\begin{array}{l}\text { Without previous } \\
\text { decompression }\end{array}$ & $48(73.8)$ & $7.98( \pm 2.12)$ & $4.5( \pm 2.33)$ & $<0.0001$ & $6.69( \pm 2.78)$ & $3.67( \pm 2.28)$ & $<0.0001$ \\
\hline $\begin{array}{l}\text { With previous } \\
\text { decompression }\end{array}$ & $17(26.2)$ & $7.65( \pm 2.45)$ & $4.82( \pm 2.56)$ & $<0.0024$ & $6.94( \pm 2.68)$ & $5.29( \pm 2.91)$ & 0.0958 \\
\hline \multicolumn{8}{|c|}{ Short-term follow-up ( $<100 \mathrm{wk}$ ) } \\
\hline Complete cohort & $34(100)$ & $6.88( \pm 2.83)$ & $4.00( \pm 2.51)$ & $<0.0001$ & $6.91( \pm 2.53)$ & $2.49( \pm 1.77)$ & $<0.0001$ \\
\hline $\begin{array}{l}\text { Without previous } \\
\text { decompression }\end{array}$ & $27(81.8)$ & $6.76( \pm 3.03)$ & $3.83( \pm 2.49)$ & $<0.0002$ & $4.69( \pm 2.48)$ & $1.89( \pm 0.32)$ & $<0.0001$ \\
\hline $\begin{array}{l}\text { With previous } \\
\text { decompression }\end{array}$ & $6(18.2)$ & $7.6( \pm 0.89)$ & $5.0( \pm 2.65)$ & $<0.0709$ & $6.2( \pm 2.68)$ & $5.8( \pm 2.86)$ & 0.8254 \\
\hline \multicolumn{8}{|c|}{ Long-term follow-up (>100 wk) } \\
\hline Complete cohort & $31(100)$ & $7.00( \pm 2.62)$ & $3.94( \pm 2.29)$ & $<0.0001$ & $5.39( \pm 2.77)$ & $3.14( \pm 2.61)$ & $<0.0023$ \\
\hline $\begin{array}{l}\text { Without previous } \\
\text { decompression }\end{array}$ & $21(65.6)$ & $6.58( \pm 2.41)$ & $3.42( \pm 1.95)$ & $<0.0001$ & $4.21( \pm 2.1)$ & $1.69( \pm 0.49)$ & $<0.0001$ \\
\hline $\begin{array}{l}\text { With previous } \\
\text { decompression }\end{array}$ & $11(34.4)$ & $7.67( \pm 2.90)$ & $4.75( \pm 2.63)$ & 0.0171 & $7.25( \pm 2.73)$ & $5.08( \pm 3.03)$ & 0.0794 \\
\hline
\end{tabular}

Abbreviation: NRS, numerical rating scale; SD, standard deviation. 
significance but a trend was found with respect to leg pain (6.94 versus $5.29 ; p=0.0958$ ).

When dichotomizing the 65 patients according to the follow-up (short term versus long term), similar results were found for the complete cohort and patients without previous lumbar decompression with significant reduction in back pain and leg pain. Patients with previous decompression showed a significant reduction of back pain in the long-term follow-up. For other parameters within this group, a trend was found that also assumes a postoperative benefit without being significant (-Table $\mathbf{5}$ ).

To exclude the influence of the surgical procedure on the postoperative amount of pain, the pre- and postoperative NRS for back pain and leg pain were analyzed on the complete cohort with respect to the sample size showing similar and significant reduction in back pain and leg pain on the NRS, independent from the procedure of decompression (data not shown).

\section{Discussion}

Lumbar spinal stenosis is one of the most common specific disorders causing radiating leg pain, spinal claudication, and associated lower back pain. ${ }^{16}$ The numbers of surgical procedures for spinal stenosis in Europe and the United States, especially for elderly patients, have more than doubled during the last decade. ${ }^{17,18}$

Lumbar spinal stenosis can be treated conservatively in the absence of neurologic deficits and as long as the patient has a good response to medical pain treatment. However when these treatment options fail, surgical treatment can be considered. Prospective studies showed an distinct advantage of surgical therapy over conservative treatment in patients without instability regarding pain and physical function. ${ }^{3,19,20}$ In patients with segmental macro-instability or severe deformity, clear evidence indicated additional fusion or fixation had an even better clinical outcome. ${ }^{21}$ For the remaining patients, the ideal treatment option is still unresolved.

Surgical spinal decompression is one treatment option with the aim to improve radicular pain and walking distance. However, Jones et al showed that lower back pain also improves significantly after decompression surgery. ${ }^{7}$ Improvement in nutrient supply, recovery of blood flow, diathermy of the posterior primary ramus that innervates the facet joints, or posture improvement are possible explanations. ${ }^{7}$

The best treatment option for recurrent stenosis without instability after decompression is also still undefined. Rare studies report good results regarding back pain, leg pain, and disability for decompression and fusion for same-level recurrent stenosis. ${ }^{22,23}$ However, to our knowledge there are no data on re-decompression for recurrent stenosis.

Therefore, so far we have favored decompression only without fusion or fixation in the absence of segmental macro-instability or deformity, even for recurrent stenosis. This policy is the basis for our retrospective analysis of outcomes after first or revision surgery in patients with symptomatic lumbar stenosis and also represents the current state in terms of health care research.

\section{Outcome for First-Time Surgery}

Our results showed a significant reduction in back pain and leg pain on the NRS after primary decompression in patients with lumbar spinal stenosis without instability. This is in line with recent studies showing an improvement, not only for leg pain and walking distance after primary decompression, but also a significant benefit regarding back pain. ${ }^{6,7}$ Dividing the complete cohort into short-term follow-up $(<100$ weeks) and long-term follow-up ( $>100$ weeks), the positive effect of surgical decompression regarding back pain and leg pain seems to be robust. Similar results with stable and significant reduction of back pain and leg pain over a period of 1 year ${ }^{6,7}$ and 2 years ${ }^{19}$ were shown, indicating that decompression without fusion or fixation is also an appropriate treatment option in lumbar spinal stenosis with relevant back pain.

Because various approaches are available to achieve decompression, Overdevest et $\mathrm{al}^{24}$ found no significant differences in clinical results between different posterior decompression techniques in their review, although the quality of evidence was low. However, in our retrospective study, the type of decompression (unilateral, unilateral with undercutting, or bilateral) had no impact on the reduction in back and leg pain in the complete cohort.

The demographic and baseline characteristics as well as the complications rates within our cohort were comparable with other studies. ${ }^{6,8,25,26}$ However, the operation time per level and the in-hospital stay were somewhat higher in our study.

In 2013, Kaminski and Banse ${ }^{27}$ reported that the most valid determining factor for surgical time was the number of operated levels. With a statistically modeled operation time of 60.9 minutes per level, this finding is distinctly different than the operation time per level in our study with $102.1 \mathrm{~min}-$ utes for patients with primary decompression. The type of decompression also seems to play an important role for operation time as Thomé et $\mathrm{al}^{8}$ showed with 90 minutes per level for bilateral laminotomy, 77 minutes for unilateral laminotomy for bilateral decompression, and 73 minutes for laminectomy. Khoo and Fessler ${ }^{26}$ reported an operation time of 88 minutes per level with an open decompression compared with a novel technique with percutaneous microendoscopic laminotomy with bilateral decompression of 109 minutes. As in our study the operation time per decompression type was pooled and not analyzed separately, which may serve as a possible explanation for the longer operation time.

The length of inpatient stay for nonfusion patients within the literature shows a broad range from 1.8 days ${ }^{6}$ over 2.66 days ${ }^{7}$ to 4.9 days. ${ }^{28}$ Nevertheless, the length of hospital stay in our study with 6.5 days for primary decompression is longer. Because the patients' characteristics and complication rates are comparable, and the operative techniques vary between all the studies cited here, these parameters cannot serve as a compelling explanation for this difference. A more convincing alternative is the different health care policies in the corresponding countries. Comparing a study based on a German population with lumbar decompression, Kothe et $\mathrm{al}^{29}$ also reported an in-hospital stay of 6.4 days. 


\section{Outcome for Re-decompression}

Indications for reoperation are progressive leg and back pain, especially due to recurrent foraminal stenoses, remaining stenosis, disk herniations, or spondylolistheses. The risk for reoperation within the literature varies from $16.3 \%$ after open laminectomy to $5.8 \%$ after minimally invasive unilateral laminotomy in a broad follow-up period from 1 to 10 years. $^{30}$ Kim and Kwon ${ }^{31}$ analyzed the reoperation rates after decompression and decompression with fusion, showing no difference between the two groups with a rate of $14.2 \%$ within 5 years.

Although the rates of reoperation are remarkable, there is certainly a lack of evidence-based data for the best treatment option for patients with an indication for reoperation. Adogwa et al reported that re-decompression and fusion surgery led to an improvement in back pain, disability, and quality of life in elderly patients with persisting or recurrent back or radicular pain. ${ }^{22}$ Mendenhall et al showed similar results that a new neural decompression and instrumented fusion for recurrent same-level stenosis provides significant improvement in all patient-assessed outcome parameters. ${ }^{23}$ However, all of them achieved additional fusion and/or fixation.

In our retrospective analysis, we identified 17 patients with recurrent lumbar stenosis. These patients were treated solely with re-decompression without fixation and/or fusion at the index level; $57 \%(n=12)$ were additionally decompressed on an adjacent level. Remarkably, the patients showed a long-lasting effect from the re-decompression procedure, especially regarding back pain. Although, after re-decompression surgery the reduction in leg pain in our study was not significant, there is a clear trend insofar that they also benefited from a recurrent decompression as a first-step therapy instead of decompression with fusion and/or fixation. This satisfactory clinical outcome can be achieved with an isolated redecompression, avoiding the additional risk and costs of instrumentation and spinal fusion.

\section{Limitations}

Our study had several limitations including its retrospective character and the lack of radiographic parameters defining the stenosis, although patients with instability (Meyerding II or higher) or deformity were excluded. Also patients with an interspinous spacer, as a minimally invasive procedure, were not included because we do not offer this kind of implant. A longer follow-up period, especially for re-decompression, would be interesting to evaluate its ongoing success. A further limitation was the lack of a control group (e.g., fusion group and/or conservative treatment group).

\section{Conclusion}

Our results show an overall significant improvement for back pain and leg pain in patients with lumbar spinal stenosis without signs of instability or deformity treated with decompression only without fixation or fusion. Taking into account the degenerative character of lumbar spinal stenosis, some percentage of the patients develop a symptomatic recurrent stenosis, although they initially profit from decompression surgery. Therefore even re-decompression without fixation or fusion leads to a significant reduction in back pain and a distinct benefit regarding leg pain for up to 3 years. This treatment opportunity should be considered, especially in elderly patients to avoid the risks and costs of additional fixation or fusion. However, further studies are needed with respect to a longer follow-up period for solely re-decompression. Additional radiographic parameters defining the stenosis could be helpful to find the optimal treatment strategy for this common disease. We are well aware that the sample size in the re-decompression subgroup is rather small. However, due to the emphasis of the retrospective results, we have already begun a prospective series to elucidate this relevant question.

\section{Conflict of Interest}

None.

\section{References}

1 Deyo RA, Mirza SK, Martin BI, Kreuter W, Goodman DC, Jarvik JG. Trends, major medical complications, and charges associated with surgery for lumbar spinal stenosis in older adults. JAMA 2010;303(13):1259-1265

2 Weinstein JN, Lurie JD, Olson PR, Bronner KK, Fisher ES. United States' trends and regional variations in lumbar spine surgery: 1992-2003. Spine 2006;31(23):2707-2714

3 Athiviraham A, Yen D. Is spinal stenosis better treated surgically or nonsurgically? Clin Orthop Relat Res 2007;458(458):90-93

4 Chou R, Baisden J, Carragee EJ, Resnick DK, Shaffer WO, Loeser JD. Surgery for low back pain: a review of the evidence for an American Pain Society Clinical Practice Guideline. Spine 2009; 34(10):1094-1109

5 Omidi-Kashani F, Hasankhani EG, Ashjazadeh A. Lumbar spinal stenosis: who should be fused? An updated review. Asian Spine J 2014;8(04):521-530

6 Crawford CH III, Glassman SD, Mummaneni PV, Knightly JJ, Asher AL. Back pain improvement after decompression without fusion or stabilization in patients with lumbar spinal stenosis and clinically significant preoperative back pain. J Neurosurg Spine 2016;25(05):596-601

7 Jones AD, Wafai AM, Easterbrook AL. Improvement in low back pain following spinal decompression: observational study of 119 patients. Eur Spine J 2014;23(01):135-141

8 Thomé C, Zevgaridis D, Leheta O, et al. Outcome after less-invasive decompression of lumbar spinal stenosis: a randomized comparison of unilateral laminotomy, bilateral laminotomy, and laminectomy. J Neurosurg Spine 2005;3(02):129-141

9 Carragee EJ. The increasing morbidity of elective spinal stenosis surgery: is it necessary? JAMA 2010;303(13):1309-1310

10 Katz JN, Lipson SJ, Lew RA, et al. Lumbar laminectomy alone or with instrumented or noninstrumented arthrodesis in degenerative lumbar spinal stenosis. Patient selection, costs, and surgical outcomes. Spine 1997;22(10):1123-1131

11 Knaub MA, Won DS, McGuire R, Herkowitz HN. Lumbar spinal stenosis: indications for arthrodesis and spinal instrumentation. Instr Course Lect 2005;54:313-319

12 Försth P, Ólafsson G, Carlsson T, et al. A randomized, controlled trial of fusion surgery for lumbar spinal stenosis. N Engl J Med 2016;374(15):1413-1423

13 Gibson JN, Waddell G. Surgery for degenerative lumbar spondylosis. Cochrane Database Syst Rev 2005;(04):CD001352 
14 Gerling MC, Leven D, Passias PG, et al. Risk factors for reoperation in patients treated surgically for lumbar stenosis: a subanalysis of the 8-year data from the SPORT trial. Spine 2016;41(10):901-909

15 Jensen MP, Karoly P, Braver S. The measurement of clinical pain intensity: a comparison of six methods. Pain 1986;27(01): 117-126

16 Verbiest $\mathrm{H}$. A radicular syndrome from developmental narrowing of the lumbar vertebral canal. 1954. Clin Orthop Relat Res 2001; (384):3-9

17 Atlas SJ, Keller RB, Robson D, Deyo RA, Singer DE. Surgical and nonsurgical management of lumbar spinal stenosis: four-year outcomes from the Maine lumbar spine study. Spine 2000;25(05): 556-562

18 Jansson KA, Blomqvist P, Granath F, Németh G. Spinal stenosis surgery in Sweden 1987-1999. Eur Spine J 2003;12(05):535-541

19 Malmivaara A, Slätis P, Heliövaara M, et al; Finnish Lumbar Spinal Research Group. Surgical or nonoperative treatment for lumbar spinal stenosis? A randomized controlled trial. Spine 2007;32 (01):1-8

20 Weinstein JN, Tosteson TD, Lurie JD, et al; SPORT Investigators. Surgical versus nonsurgical therapy for lumbar spinal stenosis. N Engl J Med 2008;358(08):794-810

21 Liang L, Jiang WM, Li XF, Wang H. Effect of fusion following decompression for lumbar spinal stenosis: a meta-analysis and systematic review. Int J Clin Exp Med 2015;8(09):14615-14624

22 Adogwa O, Carr RK, Kudyba K, et al. Revision lumbar surgery in elderly patients with symptomatic pseudarthrosis, adjacent-segment disease, or same-level recurrent stenosis. Part 1. Two-year outcomes and clinical efficacy: clinical article. J Neurosurg Spine 2013;18(02):139-146
23 Mendenhall SK, Parker SL, Adogwa O, et al. Long-term outcomes after revision neural decompression and fusion for same-level recurrent lumbar stenosis: defining the effectiveness of surgery. J Spinal Disord Tech 2014;27(07):353-357

24 Overdevest GM, Jacobs W, Vleggeert-Lankamp C, Thomé C, Gunzburg R, Peul W. Effectiveness of posterior decompression techniques compared with conventional laminectomy for lumbar stenosis. Cochrane Database Syst Rev 2015;(03):CD010036

25 Hwang HJ, Park HK, Lee GS, Heo JY, Chang JC. Predictors of reoperation after microdecompression in lumbar spinal stenosis. Korean J Spine 2016;13(04):183-189

26 Khoo LT, Fessler RG. Microendoscopic decompressive laminotomy for the treatment of lumbar stenosis. Neurosurgery 2002;51(5, Suppl):S146-S154

27 Kaminski L, Banse X. Time spent per patient in lumbar spinal stenosis surgery. Eur Spine J 2013;22(08):1868-1876

28 Machado GC, Ferreira PH, Harris IA, et al. Effectiveness of surgery for lumbar spinal stenosis: a systematic review and meta-analysis. PLoS One 2015;10(03):e0122800

29 Kothe R, Quante M, Engler N, et al. The effect of incidental dural lesions on outcome after decompression surgery for lumbar spinal stenosis: results of a multi-center study with 800 patients. Eur Spine J 2017;26(10):2504-2511

30 Schöller K, Steingrüber T, Stein M, et al. Microsurgical unilateral laminotomy for decompression of lumbar spinal stenosis: longterm results and predictive factors. Acta Neurochir (Wien) 2016; 158(06):1103-1113

$31 \mathrm{Kim} \mathrm{JH}$, Kwon YJ. Long-term clinical and radiological outcomes after central decompressive laminoplasty for lumbar spinal stenosis. Korean J Spine 2017;14(03):71-76 